\title{
Demographic fitness of Belminus ferroae (Hemiptera: Triatominae) on three different hosts under laboratory conditions
}

\author{
Claudia Magaly Sandoval $1 /++$, Paula Medone ${ }^{2}$, Elsa Evelia Nieves ${ }^{1}$, \\ Diego Alexander Jaimes ${ }^{3}$, Nelcy Ortiz ${ }^{3}$, Jorge Eduardo Rabinovich ${ }^{2}$
}

\footnotetext{
${ }^{1}$ Laboratorio de Parasitología Experimental, Facultad de Ciencias, Universidad de Los Andes, Mérida, Venezuela ${ }^{2}$ Centro de Estudios Parasitológicos y de Vectores, Consejo Nacional de Investigaciones Científicas y Técnicas, La Plata, Argentina ${ }^{3}$ Laboratorio de Investigación en Ciencias Biomédicas, Universidad de Pamplona, Pamplona, Norte de Santander, Colombia
}

Triatominae are widely recognised for their role as vectors of Trypanosoma cruzi. One of the main biological characteristics of this subfamily is their obligate haematophagous condition. However, previous studies on Belminus herreri and Belminus ferroae suggested that cockroaches are their principal hosts in domiciles. Due to this peculiar behaviour, the aim of this study was to analyse several demographic and reproductive parameters of $\mathrm{B}$. ferroae fed on three different hosts (mice, cockroaches and Rhodnius prolixus) and relate B. ferroae fitness to these alternative hosts. The cohorts were reared under constant conditions. The egg hatching rate was similar for cohorts fed on cockroaches (69.4\%) and R. prolixus (63.8\%), but was much lower for the cohort fed on mice (16\%). The development time from the nymph to adult stage and the average age of first reproduction ( $\alpha$ ) presented lower values in the cohort fed on cockroaches, which is consistent with the higher population growth rate associated with this host. Demographic parameters [intrinsic rate of natural increase, finite rate of population growth, net reproductive rate and damping ratio] showed statistically significant differences between the cohorts. Analysis of the life history of B. ferroae revealed a higher fitness related to the cockroach. The implications of these results for the origin of the subfamily are discussed.

Key words: Triatominae - Belminus - population parameters - life-history traits - demography

The Triatominae are a subfamily of the Reduviidae (Hemiptera: Heteroptera) with 143 formally recognised species (Ayala 2009, Jurberg et al. 2009, Schofield \& Galvão 2009, Rosa et al. 2012). One of the main biological characteristics of the Triatominae is their obligate haematophagous condition: they depend on vertebrate blood to complete their life cycle (Lent \& Wygodzinsky 1979).

The genus Belminus belongs to this subfamily and is composed of eight species (Belminus rugulosus Stål, 1859, Belminus costaricensis Herrer, Lent \& Wygodzinsky, 1954, Belminus peruvianus Herrer, Lent \& Wygodzinsky, 1954, Belminus herreri Lent \& Wygodzinsky, 1979, Belminus pittieri Osuna \& Ayala, 1993, Belminus laportei Lent, Jurberg \& Carcavallo, 1995, Belminus corredori Galvão \& Angulo, 2006 and Belminus ferroae Sandoval, Pabón, Jurberg \& Galvão). The geographic range of these species includes the territories of Mexico, Costa Rica, Panama, Colombia, Venezuela, Peru and Brazil (Sandoval et al. 2007).

This genus is considered wild and is mainly found in association with bromeliads, tree bark and hollow trees

doi: 10.1590/0074-0276130211

Financial support: Universidad de Pamplona, COLCIENCIAS (112104-18236), CDCHT, ULA (C-1605-0803-A), Agencia Nacional de Promoción Científica y Tecnológica of Argentina (PICT2008-0035), ANR)/CNRS/France (ANR-08-MIE-007)

+ Corresponding author: magaly6@yahoo.com

Received 18 April 2013

Accepted 6 August 2013 as well as opossums and reptiles, whereas its members are only rarely found in human domiciliary or peridomiciliary habitats (Lent \& Wygodzinsky 1979, Gaunt \& Miles 2000). However, cases of domiciliation in Peru and Colombia have been reported (Herrer 1955, Sandoval et al. 2010).

Laboratory and field observations of B. peruvianus and $B$. herreri have indicated a diet based on a wide range of hosts, including arthropods, reptiles, birds and mammals. Furthermore, the feeding behaviour of these species is variable, ranging from cannibalism to cleptohaematophagy, haemolymphagy and haematophagy (Herrer et al. 1954, Gaunt \& Miles 2000, Sandoval et al. 2000, 2004).

Although the Belminus genus has been recognised since 1859 , vital statistics and demographic parameters have not been estimated for this group. A previous study (Sandoval et al. 2000) provided estimates for the development time and mortality of eggs and nymphs of $B$. herreri, but not for demographic parameters. This lack of information can be attributed to the sporadic capture of this species, as well as the low number of specimens collected in the field and the difficulty of rearing colonies fed on vertebrate hosts (Herrer et al. 1954, Schofield \& Galvão 2009).

Preliminary observations have indicated the possibility of rearing $B$. peruvianus by feeding it on nymphs of other Triatominae (Herrer et al. 1954). Although Rhodnius prolixus is not considered a natural host of Belminus species, using this species as a food source allows laboratory colonies of $B$. herreri to be reared, though in low numbers (Sandoval et al. 2000). A study of the intestinal contents of domiciliary-captured individuals of B. fer- 
roae (Sandoval et al. 2010) indicated mice, human blood and haemolymph as natural food sources of this species and suggested that cockroaches are its principal host.

The peculiar feeding behaviour of this genus may provide new insights into the evolutionary ecology of triatomines. Thus, the aim of the present study was to analyse several demographic features (i.e. life cycle, reproduction and mortality) and population parameters [i.e. population growth rates, age-specific reproductive value $(V)$ and the stable stage distribution (SSD)] in $B$. ferroae fed on three different types of hosts (mice, cockroaches and another species of triatomine). Estimating the population fitness parameters for $B$. ferroae fed on different hosts may help to identify the possible natural hosts of this species to better understand its evolution within the Triatominae.

\section{MATERIALS AND METHODS}

Cohort origin - The population of B. ferroae used in this study was collected in Santa Catalina, Toledo, North of Santander, Colombia $\left(07^{\circ} 07^{\prime} \mathrm{N} 72^{\circ} 24^{\prime} \mathrm{W}\right)$.

Experimental procedures - The experiment was carried out in a climatically controlled room with a constant temperature $\left(25 \pm 2^{\circ} \mathrm{C}\right)$, humidity $(70 \pm 10 \% \mathrm{RH})$ and photoperiod (12:12 h light/dark). Field-collected females were divided into three groups of 10 insects each, and each group was offered to a different host: the mice Mus musculus, nymphs of the triatomine $R$. prolixus or nymphs of Blaberus sp. cockroaches. The eggs of these females were collected daily until hatching and the emerged nymphs I were placed with the same host as their respective field group. In the mice-fed group, the nymphs were fed on sedated $\left(\operatorname{Ketalar}^{\circledR} 75 \mathrm{mg} / \mathrm{Kg}\right.$ ) host for $3 \mathrm{~h}$ once a week. In the triatomine-fed group, first and second instar nymphs of $B$. ferroae were individually offered two $R$. prolixus fifth instar nymphs that were previously engorged on chicken blood, whereas $B$. ferroae third, fourth and fifth instar nymphs were individually fed on seven $R$. prolixus fifth instar nymphs; in the latter case, the $R$. prolixus specimens were replaced weekly. In the cockroach-fed group, the B. ferroae nymphs of all stages were placed individually with one fourth or fifth instar nymphs of Blaberus sp. The cockroaches were replaced monthly and maintained with a mixture of rabbit food, corn and water in cotton. The $B$. ferroae nymphs fed on mice and $R$. prolixus were individually maintained in $4 \times 3 \mathrm{~cm}$ containers with vertically positioned strips of paper, covered with a nylon mesh held in place with an elastic band. The $B$. ferroae nymphs fed on cockroaches were individually maintained in $10 \times 7 \mathrm{~cm}$ containers with vertically positioned strips of paper and the lid covering the container was perforated to prevent condensation and mold growth.

The three cohorts were followed up simultaneously from eggs hatched within a period of three months and initiated with 86,88 and 90 first instar nymphs on cockroach, mice and $R$. prolixus, respectively. Each individual was placed in a container by itself and each container was marked with a code, allowing an individual follow up of the cohorts and recording of the events experienced by each insect. The three cohorts were checked daily for mortality and ecdysis during the nymphal stage cycle. For each cohort, as the adults emerged, 25 couples were set up, each in an individual container and maintained under the same rearing conditions used for the nymphs. Mortality and oviposition were recorded weekly until the death of the last adult. A total of 600 eggs from these adult couples ( 200 per cohort) were checked daily to estimate the duration of embryonic development (separately for each cohort). As the cohorts were initiated with first instar nymphs, the hatching success was estimated from the total ovoposited eggs per all females in each cohort also used for backwards projection of the initial number of eggs for life table analysis. The procedures for the use of animals were conformed to the Colombian law (National Statute for the Protection of Animal, Law 84, 1989 and Resolution 8430, 1993, from the Colombian Ministry of Health).

Statistical analyses - Daily mortality data were used to calculate survival as a function of age $\left(l_{x}\right)$ and the number of eggs collected weekly was used to calculate female age-specific fecundity $\left(m_{x}\right)$. Additionally, we estimated the oviposition intermittence, which was calculated for each female as the average time between two successive oviposition bouts. Furthermore, the $l_{x}$ and $m_{x}$ schedules allowed demographic parameters such as the intrinsic rate of natural increase $\left(r_{0}\right)$ (using the Euler equation) the finite rate of natural increase $(\lambda)$, the net reproductive rate $\left(R_{o}\right)$, the mean generation time $\left(T_{\mathrm{p}}\right)$, the $V_{x}$ (Fisher 1930) and the SSD to be calculated. Definitions of these parameters, together with the formulae used for their calculation, are given in the Appendix of Rabinovich and Nieves (2011). For each demographic parameter, we also estimated the confidence interval (CI) at the $95 \%$ significance level based on 1,000 bootstrap samples created by random resampling with replacement from the initial individuals of each cohort. All of the above calculations were carried out using a unique computer program developed in the Delphi Language that was previously tested on triatomines (Medone et al. 2012). Due to the irregularity of the $m_{r}$, we fitted these results to a generalised additive model (GAM) function using R software (R Development Core Team 2007) to provide a general pattern of the distribution of the reproductive effort with age.

For construction of the Leslie matrix and to perform the elasticity analysis and damping ratio $(\rho)$ calculations, we used PopTools, which is a Microsoft Excel tool developed by Hood (2010). Differences in the development time for all instars between cohorts were assessed for significance using the Mann Whitney $U$ test at the 95\% $\mathrm{CI}$, while differences in the sex ratio and stage mortality between cohorts were analysed using a comparison of proportions based on the chi-square test for two independent samples; the last two statistical methods were carried out with MedCalc software version 11.6.1.0.

We estimated the instantaneous birth rate $(b)$ and death rate $(d)$ and calculated the probability of colonisation success (Rabinovich 1974) estimated as the ratio between the $r_{0}$ and the $b$. 


\section{RESULTS}

Vital statistics - Table I provides a statistical summary of the life-cycle of each cohort. The differences in embryonic development times between cohorts were statistically significant. The development times of all nymphs were significant, except for second instars nymphs between cohorts fed on cockroaches and $R$. prolixus. The total development time from egg to adult was similar for the cohorts fed on mice and $R$. prolixus and longer than for the cohort fed on cockroaches. The cohort fed on cockroaches showed the maximum adult longevity among the cohorts, with male longevity being greater than that of females $(p<0.0001)$. However, no statistically significant differences in longevity were found between both sexes when cohorts fed on mice and $R$. prolixus were compared ( $\mathrm{p}>0.7000)$. The maximum lifespan was observed in one male fed on cockroaches who reached an age of 1,155 days (approximately 3.2 years). No difference was found in the sex ratio [/ $(\hat{\sigma}++)]$ between the cohorts fed on each type of host.

The egg hatching rates were similar for cohorts fed on cockroaches (69.4\%) and $R$. prolixus $(63.8 \%)$, which were both much higher than the hatching rate of the cohort fed on mice $(16 \%)$. Nymphal mortality showed the classical pattern reported among Triatominae (Medone et al. 2012) with high mortality being observed in the younger stages (Table I). Total nymphal mortality, from the first instar to the adult stage, was more similar be- tween the cohorts fed on mice and $R$. prolixus $(\approx 40 \%)$ compared to that fed on cockroaches (30\%). Fig. 1 shows the female age-specific survival of the three cohorts.

Table II provides a statistical summary of reproductive traits for $B$. ferroae fed on each type of food source. The fecundity rate, estimated as the average number of eggs laid per female per reproductive week (eggs/O/reproductive week), was different between the cohorts fed on cockroaches (3.2) and mice (3.6) $(\mathrm{p}=0.0056)$, both of which showed higher rates than the cohort fed on $R$. prolixus $(0.8)(\mathrm{p}<0.0001)$. The average time from egg stage to first reproduction in a cohort $(\alpha)$ was $28.8,37.9$ and 53.9 weeks for the cohorts fed on cockroaches, mice and $R$. prolixus, respectively. The reproductive period (RP) of each cohort, measured from the earliest oviposition age to the latest oviposition age, was 109 weeks for the cohort fed on cockroaches, 95 weeks for that fed on mice and 87 weeks for the cohort fed on R. prolixus (results not shown in Table II). When comparing the average female RP (defined as the average of the difference between the last and the 1st age of reproduction for each individual female among all females) the differences between cohorts were even greater: the cohort fed on cockroaches displayed an RP of 77.8 weeks (which was 1.8 and 1.9 times longer than the RPs of the cohorts fed on mice and $R$. prolixus, respectively) (Table II).

The $m_{x}$ of $B$. ferroae showed an extremely irregular pattern associated with the three feeding sources. The

TABLE I

Vital statistics of Belminus ferroae fed on different food sources

\begin{tabular}{|c|c|c|c|c|c|c|c|c|c|c|c|c|}
\hline \multirow[b]{4}{*}{ Stage } & \multicolumn{12}{|c|}{ Food source } \\
\hline & \multicolumn{4}{|c|}{$\begin{array}{c}\text { Cockroaches } \\
\text { (Blaberus sp. haemolymph) }\end{array}$} & \multicolumn{4}{|c|}{$\begin{array}{c}\text { Mice } \\
\text { (Mus musculus blood) }\end{array}$} & \multicolumn{4}{|c|}{$\begin{array}{c}\text { Rhodnius prolixus } \\
\text { (haemolymph or blood) }\end{array}$} \\
\hline & & & Lower-upper & & & & Lower-upper & & & & Lower-upper & \\
\hline & $\mathrm{n}$ & DT & $95 \%$ CI & M & $\mathrm{n}$ & DT & $95 \%$ CI & M & $\mathrm{n}$ & DT & $95 \%$ CI & M \\
\hline Egg & 86 & $24.3^{a}$ & $23.9-24.6$ & $30.6^{f}$ & 88 & $25.7^{b}$ & $25.4-25.9$ & $83.9^{g}$ & 90 & $24.9^{c}$ & $24.4-25.2$ & $36.2^{f}$ \\
\hline Nymph I & 67 & $22.6^{a}$ & $21.4-23.7$ & $22.1^{f}$ & 64 & $38.1^{b}$ & $35.5-40.6$ & $27.3^{f}$ & 84 & $25.3^{c}$ & $24.4-26.2$ & $6.7^{g}$ \\
\hline Nymph II & 62 & $22.2^{a}$ & $20.9-23.6$ & $7.5^{f}$ & 56 & $35.9^{b}$ & $33.0-38.9$ & $12.5^{f}$ & 71 & $23.5^{a}$ & $22.5-24.6$ & $15.5^{f}$ \\
\hline Nymph III & 58 & $25.9^{a}$ & $24.2-27.6$ & $6.4^{f}$ & 54 & $36.6^{b}$ & $32.9-40.2$ & $3.6^{f}$ & 65 & $27.9^{c}$ & $26.6-29.3$ & $8.4^{f}$ \\
\hline Nymph IV & 52 & $30.2^{a}$ & $27.8-32.5$ & $10.3^{f}$ & 53 & $39.7^{b}$ & $36.1-43.3$ & $1.8^{f}$ & 64 & $47.2^{c}$ & $43.7-50.6$ & $1.5^{f}$ \\
\hline Nymph V & 50 & $39^{a}$ & $36.9-41.1$ & $3.8^{f}$ & 51 & $44.2^{b}$ & $42.3-46.2$ & $3.8^{f}$ & 63 & $75.9^{c}$ & 71.7-80.1 & $1.6^{f}$ \\
\hline Nymph I-V & 50 & $139.7^{a}$ & $135.2-144.2$ & $41.9^{f}$ & 51 & $195.3^{b}$ & $187.0-203.5$ & $42^{f}$ & 63 & $199.4^{c}$ & $193.5-205.2$ & $30^{f}$ \\
\hline Male & 25 & $789^{a, d}$ & $746.7-831.3$ & - & 25 & $378.8^{b, d}$ & $312.5-445.1$ & - & 31 & $399^{b, d}$ & $317.1-480.9$ & - \\
\hline Female & 25 & $616.7^{a, e}$ & $566.4-667.1$ & - & 26 & $371.1^{b, d}$ & $303.3-438.9$ & - & 32 & $412.1^{b, d}$ & $324.7-499.6$ & - \\
\hline Adults & 50 & $702.9^{a}$ & $661.3-744.4$ & - & 51 & $374.9^{b}$ & $326.8-423.0$ & - & 63 & $405.7^{b}$ & $345.0-466.4$ & - \\
\hline Sex ratio & $0.49^{h}$ & & & & $0.59^{h}$ & & & & $0.51^{h}$ & & & \\
\hline
\end{tabular}

development time and longevity values followed by different letters $(a-c)$ were significantly different between cohorts. Longevity values followed by different letters $(d, e)$ were significantly different (Mann Whitney's $U$ test, $\mathrm{p} \leq 0.05$ ) between sexes within cohorts. Stage-specific mortality and sex ratio $[(+/(\hat{\jmath}++)]$ values followed by different letters $(f-h)$ were significantly different $($ comparison of proportions based on the chi-square test). The number of eggs for the life table analysis was estimated (see Materials and Methods) as 124, 547 and 141 for cockroaches, mice and R. prolixus, respectively. CI: confidence interval; DT: average development time and longevity (days); M: stage-specific mortality percentage; n: number of individuals that completed each stage. 
reproductive effort per female in relation to age, averaged among females is shown in Fig. 1, after fitting the data to a GAM to smooth the laboratory results and capture the main trends. The results of the analysis of the continuity of the fecundity effort are shown in Fig. 2. The histogram of the intermittence between fecundity bouts is shown in Fig. 2A; the average intermittence was 1.7, 1.4 and 4.6 weeks for the cohorts fed on cockroaches, mice and $R$. prolixus, respectively. Fig. $2 \mathrm{~B}$ shows the interplay of the intermittence between egg-laying bouts (in weeks), total reproductive effort (eggs/P/life) and the length of the RP (also in weekly units). The contour lines and areas show that egg-laying bouts become more dispersed in time (higher intermittence) as the reproductive effort decreases and the length of the RP increases. This relationship shows a dominant trend that, for a given reproductive effort in terms of fecundity, an extension of the RP is related with an increase of the intermittence between egg-laying bouts. To show this relationship with the different food sources used in our experiments, we overlaid the dots representing the "strategy" of each of the 25 individual females with different colours for individuals feeding on each host.

Population growth parameters - Significant differences were observed between the cohorts feeding on different food sources for the following three population growth rates (Table III): the $r_{0}, \lambda$ and the $R_{o}$. No statistically significant differences were observed among cohorts in terms of their $T_{g}$.

The adult stage showed the highest $V_{x}$ followed by fifth instar in the three B. ferroae cohorts (Fig. 3A). The cohort fed on mice presented the highest $V_{x}$ curve and the one fed on R. prolixus the lowest. However, when the reproductive values were expressed in a relative scale (normalised to $100 \%$, so that the area under the curve is the same for all cohorts) (Fig. 3B), B. ferroae feeding on
$R$. prolixus showed a different reproductive curve than the other two cohorts, with an outstanding peak about 11 weeks after entering the adult stage.

The eggs were the dominant stage in the SSD in the cohorts fed on cockroaches and mice (in the classic stage pyramid form), while the adults were the dominant stage in the cohort fed on $R$. prolixus (Fig. 4).

The $\rho$ were $1.0182,1.0130$ and 1.0125 for B. ferroae fed on cockroaches, mice and $R$. prolixus, respectively, indicating that, if perturbed from the SSD, populations fed on cockroaches would recover an SSD more rapidly than populations fed on mice or $R$. prolixus.

The probability of colonisation success, estimated as the ratio between the $r_{0}$ and the $b$, was greater for the cohorts fed on cockroaches $(0.6312)$ and $R$. prolixus $(0.5067)$ than for the cohort fed on mice $(0.2550)$ (Table III). The cohort fed on $R$. prolixus showed the lowest $d$ $(0.0351)$ followed by the cohort fed on cockroaches $(d=$ $0.0593)$ and that fed on mice $(d=0.1388)$ (Table III).

Elasticity analysis - Fig. 5A, B show the elasticity of the $\lambda$ to age-specific survival and fecundity for the three $B$. ferroae cohorts. For all cohorts the survival elasticity was constant during the nymphal stages and progressively decrease in the adult stage. The elasticity of $\lambda$ to fecundity in the cohort fed on cockroaches showed the earliest and the maximum value among all cohorts, in agreement with its lower age at first reproduction $(\alpha)$ and its higher fecundity. The stage-specific elasticity (estimated from the stage-specific transition matrix) showed a maximum value for adult survival and a minimum for fecundity in the cohort fed on $R$. prolixus; these results are in agreement with the high $\alpha$ and low fertility observed in B. ferroae fed on R. prolixus. The contribution of the survival of the fifth instar nymph and adult stages to $\lambda$ was greater than that of the younger pre-adult stages (between 1-7 times greater in the cohorts fed on cockroaches and mice and 2-14 times greater in the cohort fed on R. prolixus).
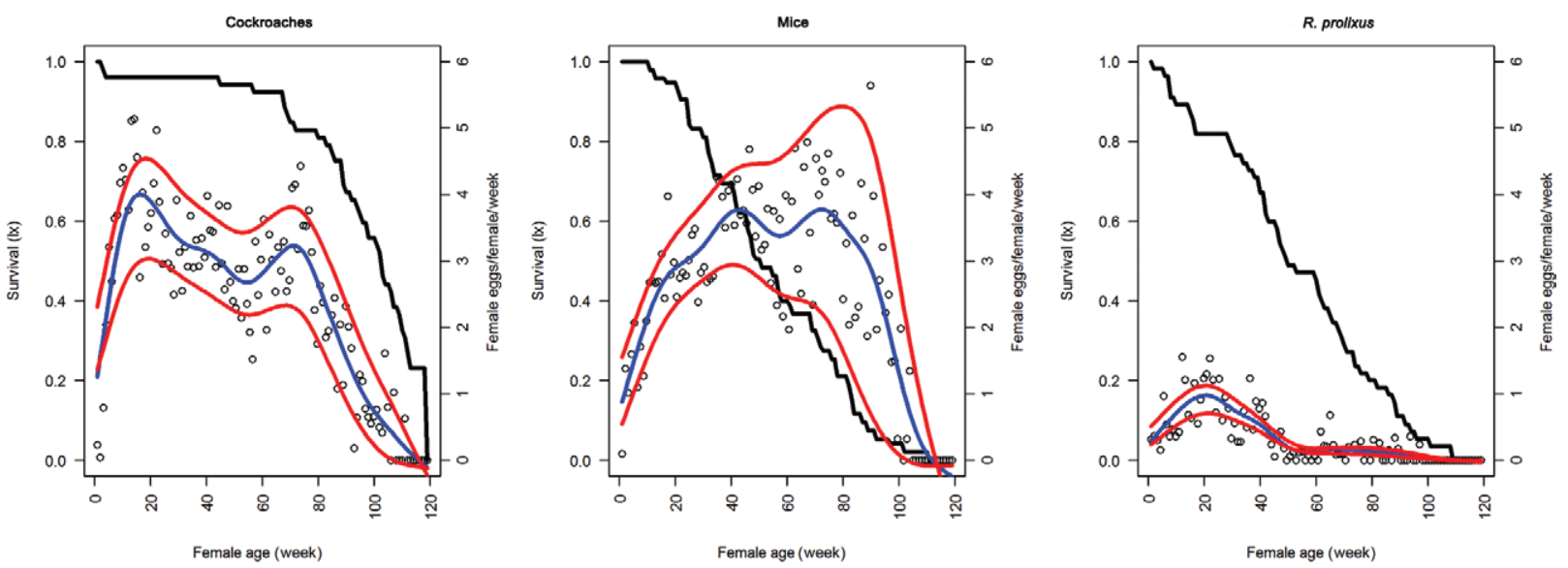

Fig. 1: female age-specific survival $\left(l_{x}\right)$ (black line) and female age-specific fecundity $\left(m_{x}\right)$ (dots) for Belminus ferroae fed on cockroaches, mice and Rhodnius prolixus. The bootstrapped $(\mathrm{n}=1000) m_{x}$ values and their lower $95 \%$ confidence limits were fitted with a generalised additive model, blue line and red lines, respectively. The age axis (weeks) represents the age of the adult female stage, so the $l_{x}$ values also represent the $l_{x}$ of the adult females (starting with $l_{0}=1$ ). 


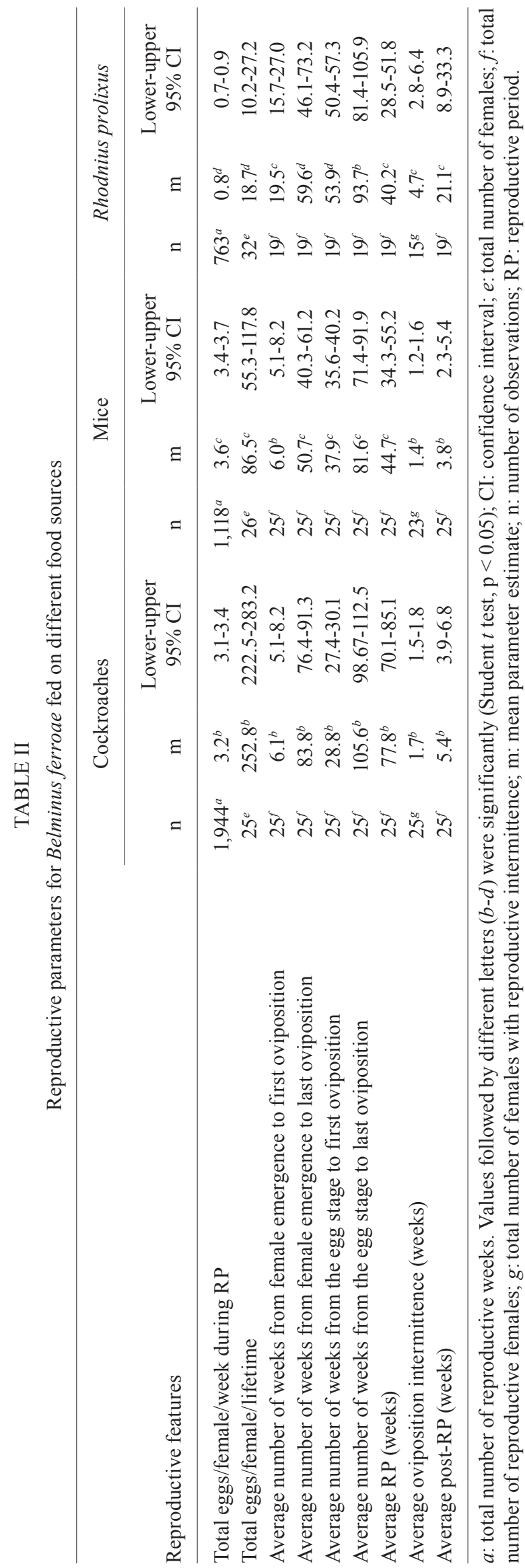

\section{DISCUSSION}

Our results are in agreement with the poor performance reported for laboratory colonies of $B$. herreri fed on $R$. prolixus (Sandoval et al. 2000). While the first three instar nymphs of $B$. ferroae develop without major difficulties when fed on R. prolixus, this is not the case for the fourth and fifth instar nymphs which showed the longest development times of the three cohorts (Table I). $R$. prolixus fifth instar nymph are possibly a prey too small for these advanced stages of $B$. ferroae and it may be difficult to extract a complete meal from instars of this size. We cannot exclude the possibility that fifth instar nymph of $R$. prolixus may exhibit defensive behaviour because their survival can be seriously compromised (no behavioural observations were carried out). Similar difficulties of $B$. ferroae adults when feeding on $R$. prolixus may be the cause of the delay in the females' age of first reproduction and the decline of other reproductive traits, such as the $R_{0}$, the $r_{0}$ and the $\lambda$, as compared to the cohorts fed on the other two hosts (Table III).

The average age of first reproduction $(\alpha)$ is an important parameter in population dynamics because it has a strong influence on the demographic rate of growth (the shorter the $\alpha$ value, the higher the rate of growth). The cohorts fed on mice and $R$. prolixus showed similar and much greater $\alpha$ values than the cohort fed on cockroaches, which is consistent with the much higher population growth rate in the latter cohort, indicating higher fitness and suggesting higher adaptation to cockroach-type arthropods as a food source.

The lack of a statistically significant difference in the sex ratio between cohorts suggests that females display the same relative mortality risk as males during development when fed on any of the three hosts used in this study.

The significant delay in the development time of the younger instar nymphs (1st, 2nd and 3rd) when fed on mice (Table I) might reflect the greater difficulty of practicing haematophagy observed in B. ferroae first instar nymphs, as indicated by the greater number of food intakes compared with other stages (data not shown), which is unusual among Triatominae (Emmanuelle-Machado et al. 2002, Martínez-Ibarra et al. 2003, 2007, Rocha et al. 2004, Arévalo et al. 2007). In Triatoma circummaculata, which is a species found in association with cockroaches of the Hiereoblatta and Blaptica genera, high mortality of first instar nymphs was observed when they were fed on vertebrate hosts (a bird and a reptile) compared with those fed on cockroaches (Ruas-Neto et al. 2001). In Triatoma rubrovaria, complete development from egg to adult is seriously compromised when this species is fed exclusively on invertebrate hosts (cockroaches), resulting in over 90\% mortality (Lorosa et al. 2000). This level of mortality is similar to that obtained in B. ferroae fed on the vertebrate host in the present study (91\%). In contrast, the two cohorts of $B$. ferroae fed on arthropods developed from the egg to adult stage with mortality rates of between $56-60 \%$, which is similar to or even lower than the rates reported for other species of Triatominae fed on their natural vertebrate hosts (Bar et al. 2003, Martínez-Ibarra et al. 2003, 2007, Villacís et al. 2008). 
It is known that in triatomines the reproductive performance of females (total number of eggs laid per female and duration of the RP) is affected by and vary with the food source (Guarneri et al. 2000, Nattero et al. 2011). We evaluated this effect using for the first time an estimation of the intermittence between reproductive bouts: $B$. ferroae fed on mice showed no differences in the intermittence between two successive reproductive bouts compared to those fed on cockroaches (Table II) and the $m_{x}$ was similar to that reported for other triatomine species reared under laboratory conditions (Rabinovich 1972, Feliciangeli \& Rabinovich 1985, Rabinovich \& Nieves 2011). This result may indicate that blood provides sufficient nutritional resources to allow an oviposition rhythm similar to that observed in $B$. ferroae fed on cockroaches. However, in the cohort fed on mice, the length of the RP and the egg hatching rate were significantly reduced compared with the cohort fed on cockroaches. This finding would seem to reflect a higher reproductive cost in B. ferroae when fed on blood as compared with haemolymph.

The relationship between the length of the RP, total lifetime number of eggs per female and intermittence between egg-laying bouts observed in $B$. ferroae when fed on $R$. prolixus was conspicuously different compared with those fed on cockroaches and mice: all females laid eggs in a highly intermittent fashion and the linear regression of the reproductive effort with the RP showed a much smaller slope. These results for the cohort fed on $R$. prolixus, together with the longest time between
A

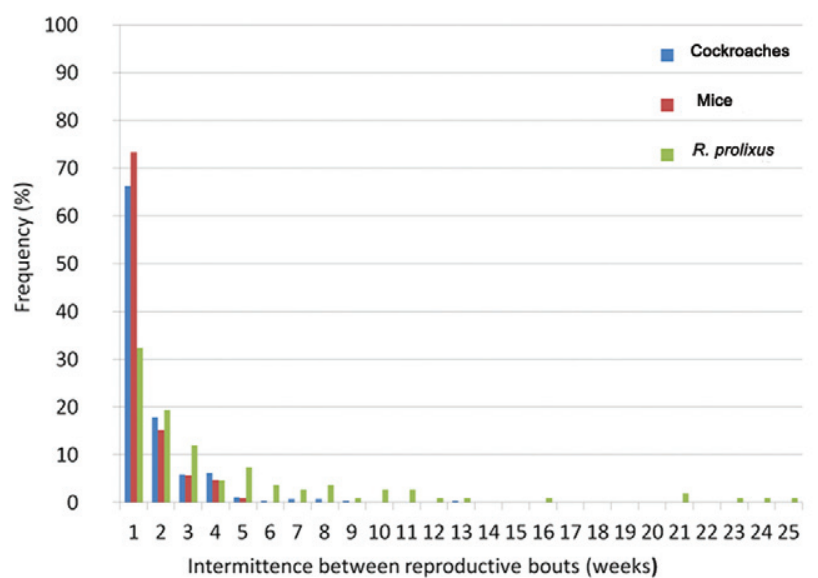

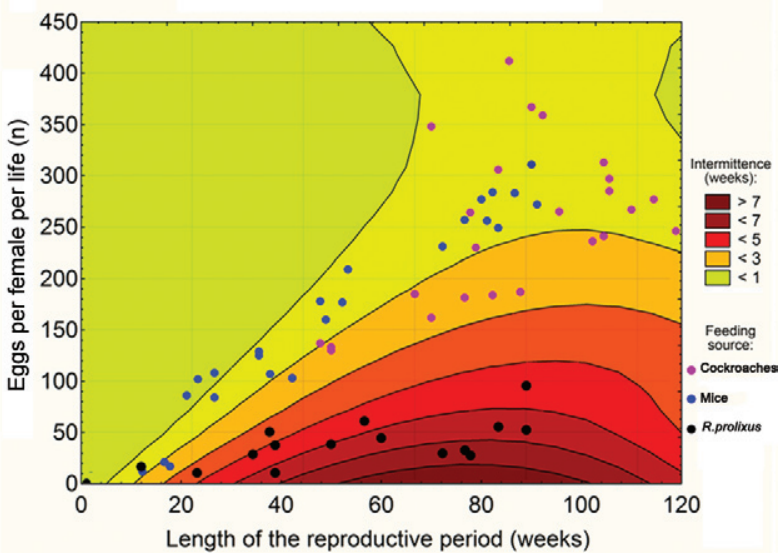

Fig. 2: intermittence between egg-laying bouts (weeks) for the cohorts fed on cockroaches, mice and Rhodnius prolixus. A: frequency distribution of intermittence; B: intermittence values given as contour lines and coloured areas (in week units) associated with total reproductive effort (eggs/ $/$ /life) and the length of the reproductive period. The dots represent the value of each reproductive individual female belonging to a given cohort as identified by the solid circle colours.

TABLE III

Population growth parameters for Belminus ferroae fed on different food sources

\begin{tabular}{|c|c|c|c|c|c|c|c|c|c|}
\hline \multirow[b]{3}{*}{ Demographic parameters } & \multicolumn{3}{|c|}{ Cockroaches } & \multicolumn{3}{|c|}{ Mice } & \multicolumn{3}{|c|}{ Rhodnius prolixus } \\
\hline & & & Lower-upper & & & Lower-upper & & & Lower-upper \\
\hline & $\mathrm{n}$ & $\mathrm{m}$ & $95 \%$ CI & $\mathrm{N}$ & $\mathrm{m}$ & $95 \%$ CI & $\mathrm{N}$ & $\mathrm{m}$ & $95 \% \mathrm{CI}$ \\
\hline Generation time & 50 & $66.6^{a}$ & $63.7-69.0$ & 51 & $65.9^{a}$ & $61.2-69.9$ & 63 & $68.7^{a}$ & $65.7-72.8$ \\
\hline Net reproductive rate & 50 & $107.5^{a}$ & $82.4-132.5$ & 51 & $14.9^{b}$ & $10.6-20.1$ & 63 & $10.3^{b}$ & $6.5-15.1$ \\
\hline Intrinsic rate of natural increase & 50 & $0.1015^{a}$ & $0.0927-0.184$ & 51 & $0.0476^{b}$ & $0.0404-0.054$ & 63 & $0.0361^{c}$ & $0.028-0.0423$ \\
\hline Finite rate of population growth & 50 & $1.107^{a}$ & $1.097-1.115$ & 51 & $1.049^{b}$ & $1.041-1.055$ & 63 & $1.028^{c}$ & $1.028-1.043$ \\
\hline Instantaneous birth rate & 50 & 0.1608 & - & 51 & 0.1863 & - & 63 & 0.0712 & - \\
\hline Instantaneous death rate & 50 & -0.0593 & - & 51 & -0.1388 & - & 63 & -0.0351 & - \\
\hline Index of colonisation success & 50 & 0.6312 & - & 51 & 0.2550 & - & 63 & 0.5067 & - \\
\hline Mean mortality rate $\left(1 / \mathrm{e}_{0}\right)$ & 50 & 0.0027 & - & 51 & 0.0116 & - & 63 & 0.0031 & - \\
\hline
\end{tabular}

values followed by different letters $(a-c)$ were significantly different (Student $t$ test, $\mathrm{p}<0.05)$; $\mathrm{e}_{0}$ : expectation of life at birth (weeks); CI: confidence interval; m: mean parameter estimate; n: number of adults in the cohort. 
two successive reproductive bouts (approximately 4.5 weeks), the very long pre and post-RP and the lowest fecundity rate appear to reinforce our hypothesis that individuals of $B$. ferroae fed on $R$. prolixus might not have been able to ingest a sufficiently large meal to respond in the same manner as the B. ferroae females fed on cockroaches and mice. The latter two cohorts responded in a similar fashion and although they displayed similar intermittence values, the $B$. ferroae females fed on cockroaches appeared to exhibit a more variable reproductive effort/RP ratio, also showing more variability in their intermittence values than those fed on mice, suggesting the existence of higher plasticity when depending on this host. Determining whether this type of loose trade-off is evolutionary advantageous will require further experiments, possibly based on energetic analysis.

The significant disparity observed in egg mortality, embryonic and nymphal development times, longevity and the average RP of females between cohorts suggest a clear demographic disadvantage when feeding on a vertebrate host compared to feeding on cockroaches, which is evident by its lower population fitness $\left(r_{0}\right)$. These results indicate that blood, despite its high protein content, does not appear to be the most adequate food source for B. ferroae.

Previous studies have shown that blood represents a diet that is deficient in essential factors, such as vitamin B (Lehane 2005). To overcome this problem, the bloodsucking insects evolved by recruiting symbionts to supply vitamin B (Schaub \& Eichler 1998), while insects that use other food sources either in lieu of or combined with a blood source obtain a balanced diet and normally do not carry symbionts in their digestive tracts. However, aposymbiosis (symbiotic organisms living apart from one another) induces a number of deleterious effects in insects, including retardation of nymphal development, increased nymphal mortality rates, disturbances of blood digestion and excretion and reduction of the tracheal system (Eichler \& Schaub 2002). In adults, aposymbiosis normally does not affect the general health of the individual, though it can affect the reproductive performance of adult females (e.g., sterility has been demonstrated in tsetse flies) (Lehane 2005).
A

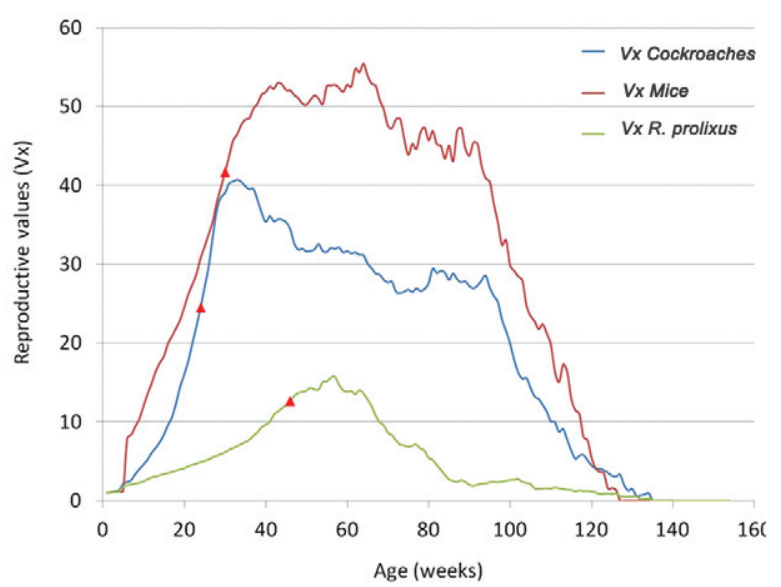

B

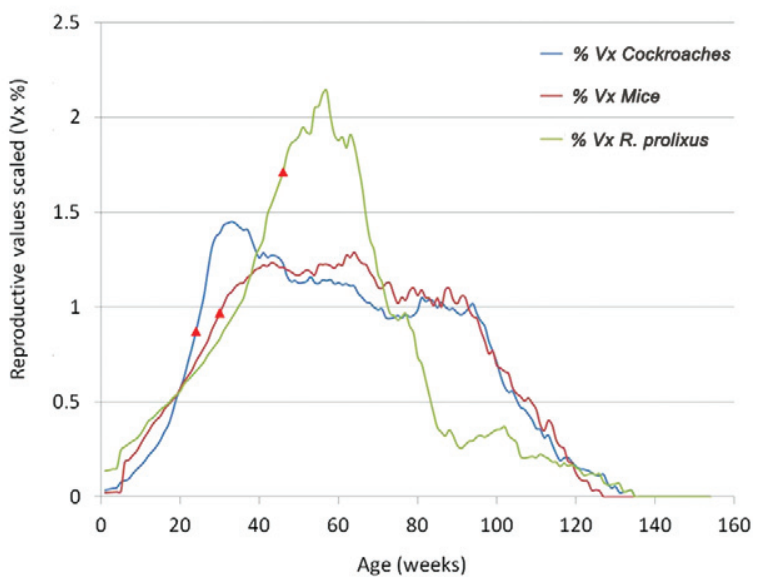

Fig. 3: age-specific reproductive values for Belminus ferroae fed on cockroaches, mice and Rhodnius prolixus. A: in arithmetic units; B: each cohort scaled as relative values with respect to their own maximum. The onset of the reproductive period (red triangle) was achieved at 24,30 and 46 weeks in the cohort fed on cockroaches, mice and $R$. prolixus, respectively; $\mathrm{V}_{\mathrm{x}}$ : reproductive value.
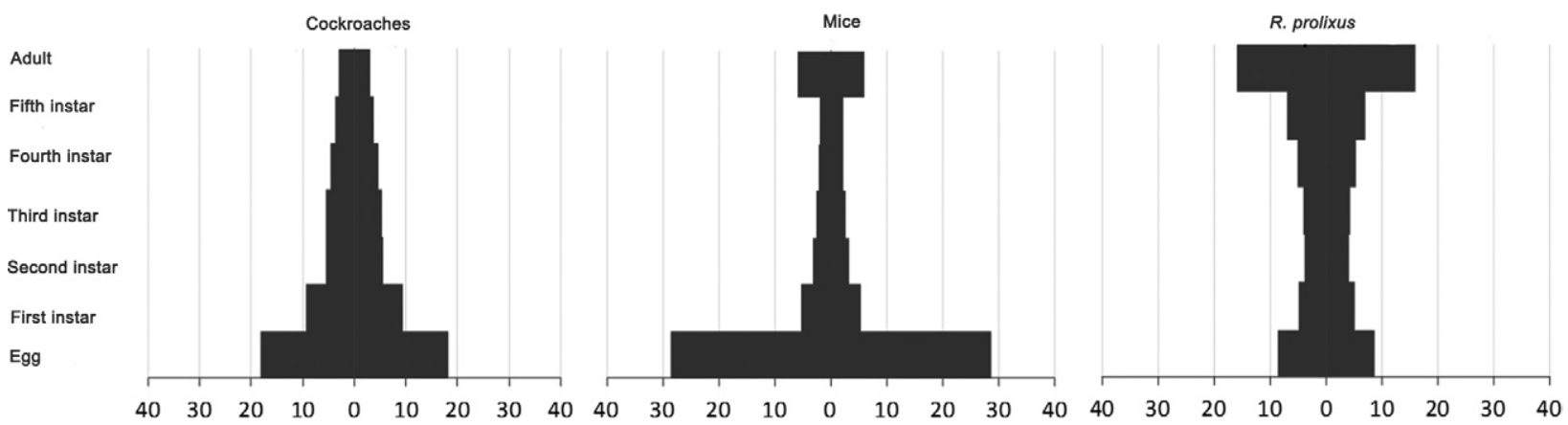

Fig. 4: stable stage distribution for the cohorts of Belminus ferroae fed on cockroaches, mice and Rhodnius prolixus. The x-axis represents the proportion of each stage as a percentage. 
Other factors associated with a blood diet are related with the digestion of haemoglobin which results in the production of large amounts of haeme, a potentially cytotoxic molecule that can exert biological damage (Maya-Monteiro et al. 2004, Graça-Souza et al. 2006, Donohue et al. 2009). A massive release of haeme represents a selective pressure that should be counteracted by the generation of an array of protective adaptations, such as the various defence mechanisms against free haeme toxicity that have been identified in $R$. prolixus (Graça-Souza et al. 2006) and the eggs of the cattle tick, Boophilus microplus (Logullo et al. 2002).

Thus, sterility due to an unbalanced diet or oxidative stress may be involved in the low fertility of the B. ferroae eggs in the cohort fed on mice. Hatching rates as low as those observed in B. ferroae fed on mice $(16 \%)$ here have never been reported in Triatominae when fed on their natural vertebrate hosts (55-100\%) (Feliciangeli \& Rabinovich 1985, Cabello \& Galíndez 1998, Guarneri et al. 2000, Martínez-Ibarra et al. 2003, 2007, Aldana \& Lizano 2004, Arévalo et al. 2007). The $V_{x}$ involves reproduction, survival and survival per age and it is difficult to establish which of these life history traits provides the dominant contribution to $V_{x}$ The high values of $V_{x}$ observed in the cohort fed on mice could be attributed to the extremely low survival probability from egg to adult stage, which could increase the importance of the reproductive contribution to the population growth rate in this cohort.

The $\rho$ is related to the time required $\left(t_{x}\right)$ to reach a stable age distribution (SAD) or SSD when a new population is being established or if a populations' age or stage distribution has been disturbed. To convert this ratio into a calendar value, we have to specify the $t_{x}$ for the second $\operatorname{root}\left(\lambda_{2}\right)$ of a Leslie matrix to contribute to a reduction of a certain multiple $(x)$ of the dominant root $(\lambda)$. Caswell (2001) showed that $t_{x}$ can be estimated as $t_{x}=\ln (x) / \ln (\rho)$, therefore a decline of $5 \%$ of the $\lambda$, implies the calculation of $t_{20}(x=1 / 0.05)$. As the maximum value of the $\rho$ for $B$. ferroae was $\rho=1.0182$ for the cohort fed on cockroach- es, its recovery time was shorter $\left(t_{20}=166\right.$ days $)$ than that of the cohort fed on $R$. prolixus ( $\rho=1.0130, t_{20}=$ 231 days); the cohort fed on mice exhibited the lowest $\rho$ (1.0125), resulting in the longest recovery period to reach a $\operatorname{SSD}\left(t_{20}=251\right.$ days). The recovery $t_{x}$ to reach an SSD in the cohort fed on cockroaches was slightly shorter than that observed in another Triatominae (Rhodnius neglectus), which was estimated at 172 days by Rabinovich and Nieves (2011).

It is of interest to compare the above theoretical $\rho$ and recovery times with SAD or SSD field values. Examination of domiciliary populations of $B$. ferroae from the locality of San Alberto, Toledo, showed that among a population of 116 individuals, $3.4 \%$ of the specimens were eggs, $56.9 \%$ were nymphs and $39.9 \%$ were adults, while in the locality of Santa Catalina, among a population of 279 individuals, $4.7 \%$ were eggs, $70.1 \%$, were nymphs and $24.4 \%$, were adults (Sandoval et al. 2010). Curiously, these SSDs conform better to the SSD predicted from the cohort fed on $R$. prolixus. Thus, either $R$. prolixus is a good alternative food source for $B$. ferroae or these field populations of $B$. ferroae are the result of recent colonisation or have had their SSD altered recently. However, these interpretations have to be considered with caution, as small nymphs display much lower catchability than larger nymphs and adults, at least in $R$. prolixus (Rabinovich et al. 1995) distorting the sampled age pyramid.

The significantly higher contribution to $\lambda$ of survival over fecundity reflects the underlying life history of $B$. ferroae, which is characterised by a long development time and long adult longevity, late maturity and low fecundity rate. These three life history traits observed in various triatomine species (Feliciangeli \& Rabinovich 1985, Cabello et al 1987, da Silva \& da Silva 1989, Cabello \& Galíndez 1998) correspond to those described by Heppell et al. (2000) for long-lived species that mature late and have few offspring, where fecundity and early offspring survival are less critical than pre-adult surviv-
A

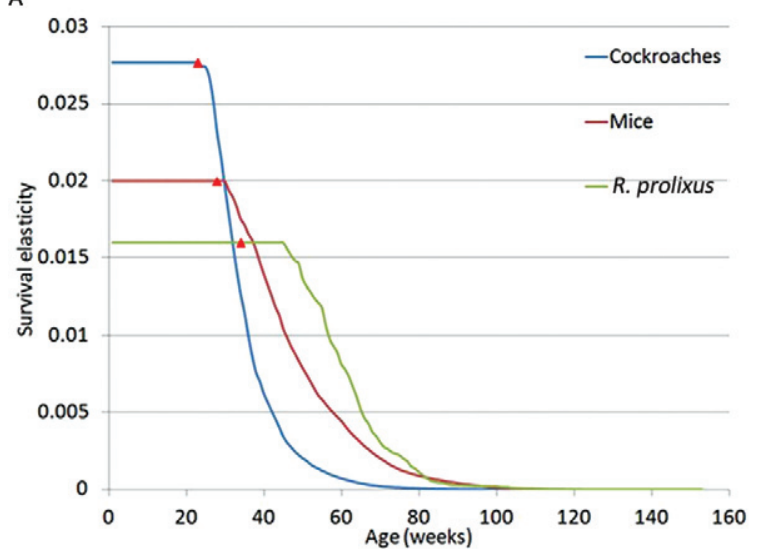

B

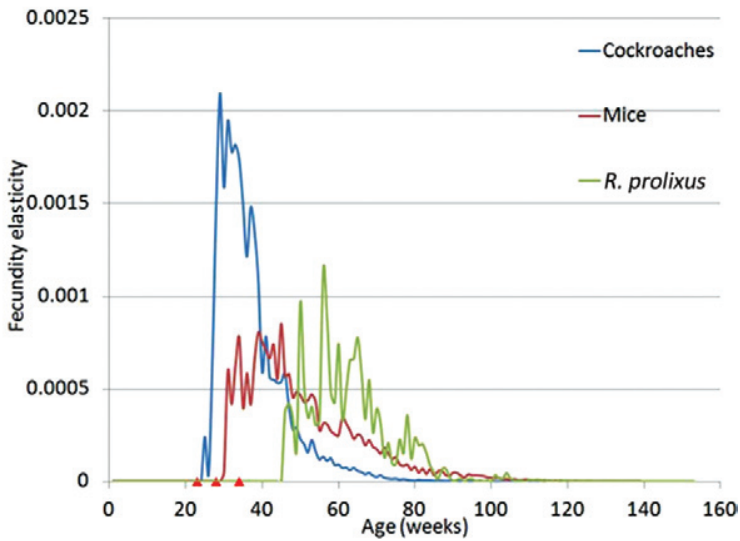

Fig. 5: age-specific elasticity of the survival (A) and fecundity (B) of Belminus ferroae fed on cockroaches, mice and Rhodnius prolixus. The age of emergence of the first adult in each cohort (red triangle) was 23, 28 and 34 weeks for the cohort fed on cockroaches, mice and $R$. prolixus, respectively. 
al to maturity [a "slow" strategy observed along several taxa, such as the "slow" mammals described by Read and Harvey (1989)]. The long development time and longevity, as well as the relatively low fecundity of $B$. ferroae, could represent an adaptive strategy for environments that are relatively "crowded" or display low food availability where selection favours efficiency of the conversion of food into offspring and minimises waste (Rabinovich 1974). The colonisation success, estimated as $r_{0} / b$, is increased not only when $r_{0}$ is large, but also when the $d$ is low (MacArthur \& Wilson 1967). Although the cohort fed on $R$. prolixus showed a significantly lower $r_{0}$ compared with the cohort fed on cockroaches, no significant difference in colonisation success was observed between those two cohorts, which could be explained by the lower $d$ of the latter $(0.0351)$ with respect to the former (0.0593). The higher probability of colonisation success observed in the cohorts fed on cockroaches provides an additional indication that arthropods may be the natural host of $B$. ferroae, implying that colonising new habitats is not critical for the domiciliary populations of this species.

The observed fecundity elasticity was approximately $35 \%$ and $45 \%$ higher in the cohort fed on cockroaches than cohorts fed on mice and $R$. prolixus, respectively. This reflects the greater relative contribution of female fecundity to $\lambda$ for the cohort fed on cockroaches, which might be due to the high fecundity values observed (between 3-14 times higher than in the cohorts fed on mice and $R$. prolixus, respectively).

From a demographic point of view, the elasticity analysis indicated that adult survival is essential for the maintenance of these populations on all of the three hosts tested and is critical in the cohort fed on $R$. prolixus. These results also confirm previous reports in Triatominae indicating that control measures targeting adult and/or fifth instar nymphs survival would be far more effective than targeting any other stage (Rabinovich \& Nieves 2011).

B. ferroae revealed a higher fitness (as measured by $\left.r_{0}\right)$ when feeding on cockroaches. This result is consistent with the fact that $B$. herreri was captured in houses where cockroaches were present and that $96 \%$ of the intestinal contents tested reacted with Periplaneta americana antiserum (Sandoval et al. 2004) and $86 \%$ in B. ferroae, while only a small proportion reacted to vertebrate blood antisera (Sandoval et al. 2010). As observed for colonisation success, the higher fitness (higher $r_{0}$ ) of the $B$. ferroae cohort fed on cockroaches reinforces the hypothesis that these arthropods could be the natural host of this species and showed for the first time the existence of a species of Triatominae without obliged bloodsucking behaviour.

From an evolutionary perspective, the following alternative hypotheses could explain why triatomines such as Belminus species show predatory behaviour: (i) Belminus is a basal group within the Triatominae, i.e., it is most closely related to the common ancestors (closer to the original entomophagous behaviour); (ii) Belminus is not a basal group and the predatory behaviour may have persisted from an ancestral plasticity related to the host (arthropod/vertebrate). This plasticity in a character that is particularly ecologically relevant to the Triatominae might have then evolved towards a predatory behaviour. This possibility is supported by the eclectic feeding behaviours, such as cannibalism, cleptohaematophagy and haemolymphagy, found in the genera Triatoma, Rhodnius, Eratyrus and Panstrongylus under both experimental (Brumpt 1914, Ryckman 1951, Piñero et al. 1988, Lorosa et al. 2000, Ruas-Neto et al. 2001) and natural conditions (Miles et al. 1981, Garrouste 2009). Such feeding eclecticism within the Triatominae represents evidence of plasticity in host preferences (Rabinovich et al. 2011) and plasticity itself can facilitate evolutionary change and speciation (Whitman \& Agrawal 2009); (iii) The Triatominae are a polyphyletic assemblage, including different tribes and species groups derived from different lineages within the predatory Reduviidae (Schofield 1988). In this case, Belminus species would be interpreted as a Reduviidae lineage at an early stage of adaptation to haematophagy, as suggested by Schofield and Galvão (2009).

In terms of the evolutionary hypotheses outlined above for the subfamily Triatominae, hypotheses (i) and (ii) imply that haematophagy evolved once in triatomine bugs. These hypotheses are consistent with monophyletic (Lent \& Wygodzinsky 1979, Hypsa et al. 2002, Weirauch \& Munro 2009, Patterson \& Gaunt 2010) and paraphyletic (Hwang \& Weirauch 2012) origins of the subfamily and would point toward the need for a broader definition of the Triatominae. The implications of hypothesis (iii) have been widely discussed by Schofield and Galvão (2009) and suggest that haematophagy arose on various occasions from arthropod-predatory ancestors, resulting in the subfamily Triatominae. However, these hypotheses can only be tested through a phylogenetic analysis of the subfamily, including species of Belminus and other representatives of the Bolboderini and Alberproseniini that have yet to be incorporated.

\section{ACKNOWLEDGEMENTS}

To Dr C Schofield, for general discussions and for suggesting this analysis, and to Waldo Hasperue, for his help in computational aspects.

\section{REFERENCES}

Aldana E, Lizano E 2004. Defecation index and reproductive success of Triatoma maculata (Hemiptera: Reduviidae) under laboratory conditions. Rev Biol Trop 52: 927-930.

Arévalo A, Carranza JC, Guhl F, Clavijo JA, Vallejo GA 2007. Comparación del ciclo de vida de Rhodnius colombiensis Moreno, Jurberg \& Galvão, 1999 y Rhodnius prolixus Stål, 1872 (Hemiptera, Reduviidae, Triatominae) en condiciones de laboratorio. Biomedica 27: 119-129.

Ayala JM 2009. Una nueva especie de Panstrongylus Berg de Venezuela (Hemiptera: Reduviidae, Triatominae). Entomotropica 24: 105-109.

Bar ME, Oscherov EB, Milano AMF, Damborsky M 2003. Ciclo de vida de Triatoma rubrovaria (Blanchard, 1843) (Heteroptera: Reduviidae) bajo condiciones de laboratorio. Facena 19: 87-95.

Brumpt E 1914. Importance du cannibalisme et de la coprofhagie chez les réduvidés hématophages (Rhodnius, Triatoma) pour la conservation des trypanosomes pathogénes en dehors de I'hote vertébré. Bull Soc Pathol Exot 7: 702-705. 
Cabello DR, Galíndez I 1998. Vital statistics of Panstrongylus geniculatus (Latreille 1811) (Hemiptera: Reduviidae) under experimental conditions. Mem Inst Oswaldo Cruz 93: 257-262.

Cabello DR, Lizano E, Valderrama A 1987. Estadisticas vitales de Rhodnius neivai Lent, 1953 (Hemiptera: Reduviidae) en condiciones experimentales. Mem Inst Oswaldo Cruz 82: 511-524.

Caswell H 2001. Matrix population models. Construction, analysis and interpretation, 2nd ed., Sinauer Associates/Inc Publishers, Massachusetts, $722 \mathrm{pp}$.

da Silva IG, da Silva HHG 1989. Estudo comparado do ciclo evolutivo de triatomíneos a duas temperaturas. Mem Inst Oswaldo Cruz 84 (Suppl. IV): 499-500.

Donohue KV, Khalil SM, Sonenshine DE, Roe RM 2009. Hemebinding storage proteins in the Chelicerata. J Insect Physiol 55: 287-296.

Eichler S, Schaub GA 2002. Development of symbionts in triatomine bugs and the effects of infections with trypanosomatids. Exp Parasitol 100: 17-27.

Emmanuelle-Machado P, Koerich LB, Joukoski DB, Carvalho-Pinto CJ, Grisard EC, Steindel M 2002. Biology of Triatoma klugi Carcavallo, Jurberg, Lent \& Galvão 2001 (Heteroptera: Reduviidae) under laboratory conditions: effects of distinct blood sources and susceptibility to Trypanosoma cruzi and Trypanosoma rangeli. Mem Inst Oswaldo Cruz 97: 583-587.

Feliciangeli MD, Rabinovich JE 1985. Vital statistics of Triatominae (Hemiptera: Reduviidae) under laboratory conditions. II. Triatoma maculata. J Med Entomol 22: 43-48.

Fisher RA 1930. The genetical theory of natural selection, 1st ed., Claredon Press, Oxford, 272 pp.

Garrouste R 2009. La première observation in natura de l'entomophagie de Panstrongylus geniculatus (Latreille 1811) hématophage vecteur de la maladie de Chagas (Hemiptera: Reduviidae). Ann Soc Entomol Fr 45: 302-304.

Gaunt M, Miles M 2000. The ecotopes and evolution of triatomine bugs (Triatominae) and their associated trypanosomes. Mem Inst Oswaldo Cruz 95: 557-565.

Graça-Souza AV, Maya-Monteiro C, Paiva-Silva GO, Braz GR, Paes MC, Sorgine MH, Oliveira MF, Oliveira PL 2006. Adaptations against heme toxicity in blood-feeding arthropods. Insect Biochem Mol Biol 36: 322-335.

Guarneri AA, Pereira MH, Diotaiuti L 2000. Influence of the blood meal source on the development of Triatoma infestans, Triatoma brasiliensis, Triatoma sordida and Triatoma pseudomaculata (Heteroptera, Reduviidae). J Med Entomol 37: 373-379.

Heppell SS, Caswell H, Crowder LB 2000. Life histories and elasticity patterns: perturbation analysis for species with minimal demographic data. Ecology 81: 654-665.

Herrer A 1955. Tripanosomiasis americana en el Perú. V. Triatominos del valle interandino del Marañón. Rev Perú Med Exp Salud Publica 9: 69-81.

Herrer A, Lent H, Wygodzinsky P 1954. Contribución al conocimiento del género Belminus Stål, 1859 (Triatominae, Reduviidae, Hemiptera). An Inst Med Reg Tucumán 4: 85-106.

Hood GM 2010. PopTools version 3.2.3. Available from: poptools.org.

Hwang WS, Weirauch C 2012. Evolutionary history of assassin bugs (Insecta: Hemiptera: Reduviidae): insights from divergence dating and ancestral state reconstruction. PLOS ONE 7: e45523.

Hypsa V, Tietz DF, Zrzavy J, Rego ROM, Galvão C, Jurberg J 2002. Phylogeny and biogeography of Triatominae (Hemiptera: Redu- viidae): molecular evidence of a New World origin of the Asiatic clade. Mol Phylogenet Evol 23: 447-457.

Jurberg J, Rocha DS, Galvão C 2009. Rhodnius zeledoni sp. nov. afim de Rhodnius paraensis Sherlock, Guitton \& Miles, 1977 (Hemiptera, Reduviidae, Triatominae). Biota Neotrop 9: 123-128.

Lehane MJ 2005. The biology of blood-sucking in insects, 2nd ed., Cambridge University Press, Cambridge, 320 pp.

Lent H, Wygodzinsky P 1979. Revision of the Triatominae (Hemiptera, Reduviidae) and their significance as vectors of Chagas disease. Bull Am Mus Nat Hist 163: 123-520.

Logullo C, Moraes J, Dansa-Petretski M, Vaz IS, Masuda A, Sorgine MH, Braz GR, Masuda H, Oliveira PL 2002. Binding and storage of heme by vitellin from the cattle tick, Boophilus microplus. Insect Biochem Mol Biol 32: 1805-1811.

Lorosa ES, Jurberg J, Souza AL, Vinhaes MC, Nunes IM 2000. Hemolinfa de Dictyoptera na manutenção do ciclo biológico silvestre de Triatoma rubrovaria (Blanchard, 1843) e Triatoma circummaculata (Stal, 1859) (Hemiptera, Reduviidae, Triatominae). Entomol Vect 7: 287-296.

MacArthur RH, Wilson EO 1967. The theory of island biogeography, 1st ed., Princeton University Press, New Jersey, 203 pp.

Martínez-Ibarra JA, Alejandre-Aguilar R, Paredes-González E, Martínez-Silva MA, Solorio-Cibrián M, Nogueda-Torres B, TrujilloContreras F, Novelo-López M 2007. Biology of three species of North American Triatominae (Hemiptera: Reduviidae: Triatominae) fed on rabbits. Mem Inst Oswaldo Cruz 102: 925-930.

Martínez-Ibarra JA, López MN, Robles MRH, Guillén YG 2003. Influence of the blood meal source on the biology of Meccus picturatus Usinger 1939 (Hemiptera: Reduviidae: Triatominae) under laboratory conditions. Mem Inst Oswaldo Cruz 98: 227-232.

Maya-Monteiro CM, Alves LR, Pinhal N, Abdalla DS, Oliveira PL 2004. HeLp, a heme-transporting lipoprotein with an antioxidant role. Insect Biochem Mol Biol 34: 81-88.

Medone P, Rabinovich J, Nieves E, Ceccarelli S, Canale D, Stariolo RL, Menu F 2012. The quest for immortality in triatomines: a meta-analysis of the senescence process in hemimetabolous hematophagous insects. Available from: intechopen.com/books/ senescence/-the-quest-for-immortality-in-triatomines-a-metaanalysis-of-the-senescence-process-in-hemimetabolou.

Miles MA, de Souza AA, Póvoa M 1981. Chagas disease in the Amazon Basin. III. Ecotopes of ten triatomine bug species (Hemiptera: Reduviidae) from the vicinity of Belém, Pará state, Brazil. J Med Entomol 18: 266-278.

Nattero J, Leonhard G, Rodríguez CS, Crocco L 2011. Influence of the quality and quantity of blood ingested on reproductive parameters and life-span in Triatoma infestans (Klug). Acta Trop 119: 183-187.

Patterson JS, Gaunt MW 2010. Phylogenetic multi-locus codon models and molecular clocks reveal the monophyly of haematophagous reduviid bugs and their evolution at the formation of South America. Mol Phylogenet Evol 56: 608-621.

Piñero DF, Carcavallo RU, Fernandez E 1988. Canibalismo y transmisión directa de Trypanosoma cruzi entre ninfas de Rhodnius prolixus. Chagas 5: 18-22.

R Development Core Team 2007. R: a language and environment for statistical computing. Available from: R-project.org.

Rabinovich JE 1972. Vital statistics of Triatominae (Hemiptera: Reduviidae) under laboratory conditions. I. Triatoma infestans Klug. J Med Entomol 9: 351-370.

Rabinovich JE 1974. Demographic strategies in animal populations: a regression analysis. In FB Golley, E Medina, Tropical ecological systems, Springer-Verlarg, New York, p. 19-40. 
Rabinovich JE, Gürtler RE, Leal JA, de Piñero DF 1995. Density estimates of the domestic vector of Chagas disease, Rhodnius prolixus Stål (Hemiptera: Reduviidae), in rural houses in Venezuela. Bull World Health Organ 73: 347-357.

Rabinovich JE, Kitron UD, Obed Y, Yoshioka M, Gottdenker N, Chaves LF 2011. Ecological patterns of blood-feeding by kissingbugs (Hemiptera: Reduviidae: Triatominae). Mem Inst Oswaldo Cruz 106: 479-494.

Rabinovich JE, Nieves EL 2011. Vital statistics of Triatominae (Hemiptera: Reduviidae) under laboratory conditions: III. Rhodnius neglectus. J Med Entomol 48: 775-787.

Read AF, Harvey PH 1989. Life history differences among the eutherian radiations. J Zool 219: 329-353.

Rocha DS, dos Santos CM, Cunha V, Jurberg J, Galvão C 2004. Ciclo biológico em laboratório de Rhodnius brethesi Matta, 1919 (Hemiptera, Reduviidae, Triatominae), potencial vetor silvestre da doença de Chagas na Amazônia. Mem Inst Oswaldo Cruz 99: 591-595.

Rosa JA, Solano RC, Gardim S, Pinto MR, Mendoça VG, Ferreira Filho JC, Carvalho EO, Camargo LM, Oliveira J, Nascimento JD, Cilense M, Almeida CE 2012. Description of Rhodnius montenegrensis $\mathrm{n}$. sp. (Hemiptera: Reduviidae: Triatominae) from the state of Rondônia, Brazil. Zootaxa 3472: 62-76.

Ruas-Neto AL, Corseuil E, Cavalleri A 2001. Development of rupestrian triatomines (Hemiptera: Reduviidae: Triatominae) following haemolymphagy on blaberids (Blattodea: Blaberidae) in Rio Grande do Sul state, Brazil. Entomol Vect 8: 205-216.

Ryckman RE 1951. Recent observations of cannibalism in Triatoma (Hemiptera: Reduviidae). J Parasitol 37: 433-434.

Sandoval CM, Duarte R, Gutíerrez R, Rocha DS, Angulo VM, Esteban L, Reyes M, Jurberg J, Galvão C 2004. Feeding sources and natural infection of Belminus herreri (Hemiptera, Reduviidae, Triatominae) from dwellings in Cesar, Colombia. Mem Inst Oswaldo Cruz 99: 137-140.
Sandoval CM, Joya MI, Gutierez R, Angulo VM 2000. Cleptohaematophagy of the Triatomine bug Belminus herreri. Med Vet Entomol 14: 100-101.

Sandoval CM, Ortiz N, Jaimes D, Lorosa E, Galvão C, Rodriguez O, Scorza JV, Gutiérrez R 2010. Feeding behaviour of Belminus ferroae (Hemiptera: Reduviidae), a predaceous Triatominae colonizing rural houses in Norte de Santander, Colombia. Med Vet Entomol 24: 124-131.

Sandoval CM, Pabón E, Jurberg J, Galvão C 2007. Belminus ferroae n. sp. from the Colombian north-east, with a key to the species of the genus (Hemiptera: Reduviidae: Triatominae). Zootaxa 1443: 55-64.

Schaub GA, Eichler S 1998. The effects of aposymbiosis and of an infection with Blastocrithidia triatomae (Trypanosomatidae) on the tracheal system of the reduviid bugs Rhodnius prolixus and Triatoma infestans. J Insect Physiol 44: 131-140.

Schofield CJ 1988. The biosystematics of Triatominae. In MW Service, biosystematics of haematophagous insects, Clarendon Press, Oxford, p. 284-312.

Schofield CJ, Galvão C 2009. Classification, evolution and species groups within the Triatominae. Acta Trop 110: 88-100.

Villacís AG, Arcos-Terán L, Grijalva MJ 2008. Life cycle, feeding and defecation patterns of Rhodnius ecuadoriensis (Lent \& León 1958) (Hemiptera: Reduviidae: Triatominae) under laboratory conditions. Mem Inst Oswaldo Cruz 103: 690-695.

Weirauch C, Munro JB 2009. Molecular phylogeny of the assassin bugs (Hemiptera: Reduviidae) based on mitochondrial and nuclear ribosomal genes. Mol Phylogenet Evol 53: 287-299.

Whitman DW, Agrawal AA 2009. What is phenotypic plasticity and why is it important? In DW Whitman, TN Ananthakrishnan, Phenotypic plasticity of insects: mechanisms and consequences, Science Publishers, New Hampshire, p. 1-63. 